\title{
Non-Traditional Administration of Remifentanil in an Experimental Setting
}

\author{
A. KURZOVÁ ${ }^{1}$, J. MÁLEK ${ }^{1}$, L. HESS ${ }^{2}$, M. JAČEK ${ }^{3}$, J. SLÍVA ${ }^{4}$ \\ ${ }^{1}$ Department of Anesthesiology and Resuscitation, Third Faculty of Medicine, Faculty Hospital \\ Královské Vinohrady, Prague, Czech Republic, ${ }^{2}$ Department of Laboratory of Experimental \\ Anesthesiology, Institute for Clinical and Experimental Medicine, Prague, Czech Republic, \\ ${ }^{3}$ Department of Hygiene, Third Faculty of Medicine, Charles University, Prague, Czech Republic, \\ ${ }^{4}$ Department of Pharmacology, Third Faculty of Medicine, Charles University, Prague, Czech \\ Republic
}

Received September 3, 2019

Accepted September 16, 2019

\begin{abstract}
Summary
Remifentanil is ultrashort-acting opioid with a unique pharmacokinetic profile. It is used exclusively intravenously. While considering its rapid onset of action and other pharmacokinetic properties, we decided to assess its effects following administration via non-traditional routes. Rabbits $(n=10$ per each group) were randomized into six groups: remifentanil $1 \mu \mathrm{g} / \mathrm{kg}$ and $3 \mu \mathrm{g} / \mathrm{kg} \mathrm{IM}, 5.0$ and $10.0 \mu \mathrm{g} / \mathrm{kg}$ conjunctivally, and $10 \mu \mathrm{g} / \mathrm{kg}$ and $25.0 \mu \mathrm{g} / \mathrm{kg}$ intranasally. Sedating effects were assessed via a loss of the righting reflex. Secondary, mean arterial blood pressure, arterial oxygen saturation of hemoglobin, and pulse rate was monitored in all rabbits. Non-traditional routes of administration were shown to provide a rapid onset of action as well as fast recovery. Importantly, the administration of remifentanil did not result in any deterioration of cardiovascular functions.
\end{abstract}

\section{Key words}

Remifentanil • Opioids • Rabbits • Pain • Non-traditional administration - Conjunctival administration • Nasal administration

\section{Corresponding author}

J. Slíva, Department of Pharmacology, Third Faculty of Medicine, Charles University, Ruská 87, 10000 Prague 10, Czech Republic. E-mail: Jiri.Sliva@lf3.cuni.cz

\section{Introduction}

In surgery, the opioids continue to play a central role in every facet of modern practice and treatment of severe acute pain. For opioids such as fentanyl and its derivatives, the ability to determine a well-tolerated and effective dose is limited by variability in both pharmacokinetics and pharmacodynamics. On the other hand, although remifentanil is a typical mu-opioid receptor agonist with pharmacodynamic properties like those of fentanyl and its derivatives, metabolism by non-specific esterases gives remifentanil a unique pharmacokinetic profile. The clinical advantage of this drug lies in its extremely rapid clearance, and therefore offset of effect, which is independent of excretory organs.

Other opioids undergo a "multicompartment" disposition, i.e. they are rapidly distributed throughout the body and are subsequently inactivated by slower hepatic biotransformation. Both these processes determine the clearance of traditional opioids, but their relative contributions may be different depending on the dose used and the route of administration (Hughes et al. 1992). Individual patients may also have markedly different distribution volumes and rates of metabolic clearance. These differences mean that the peak opioid concentration after a bolus cannot be predicted with certainty. Only a small portion of this pharmacokinetic variability can be minimized by adjusting for factors such as age, gender, weight, and drug interactions, and these 
data are not available for most opioids. Even if the plasma concentration were known precisely, it would still be difficult to predict opioid sensitivity for any individual patient. This is important because an opioid-sensitive patient will experience not only a greater intensity of effect, but also a longer effect duration, and the concentration must be lower for a normal recovery rate to occur).

We anticipate lower opioid requirements in elderly or debilitated patients and in those who have received other depressant drugs; increased requirements might be expected in opioid-tolerant individuals or those undergoing extremely painful procedures. Unfortunately, there is a large amount of interpatient variability due to factors that cannot be easily identified; ample data shows that individual patients can have a three- to fivefold range of sensitivity to a given concentration of opioid (Ausems et al. 1986). Administering a $99 \%$ effective dose to every patient will produce excessive effects in many patients and is obviously not an option in most circumstances.

In cases of severe acute pain, achieving adequate analgesia with an acceptable speed of recovery depends on how well the opioid is titrated. An overdose with any opioid can be a problem. The primary advantage of remifentanil is a reduction in pharmacokinetic variability (Glass et al. 1998). The drug is eliminated by enzymatic hydrolysis with redistribution relegated to a minor role. Remifentanil is metabolized by non-specific esterases, an enormously active group of enzymes found in blood and tissues throughout the body. Most of this hydrolysis probably occurs in skeletal muscle, and total remifentanil clearance is $30-50 \%$ of the cardiac output. Moreover, this metabolism is not subject to the same sorts of genetic variability and drug interactions as that seen with specific esterases like plasma cholinesterase (Westmoreland et al. 1993).

The clearance is predictable because it is unaffected by so many other variables (e.g. bolus versus infusion, hepatic or renal function, gender, drug interaction, etc.). The few factors that have been demonstrated to alter remifentanil clearance (e.g. age) and distribution volume (weight) do not produce great changes in the duration of action. This means that, compared with other opioids, an infusion of remifentanil will produce more consistent steady-state blood concentrations, and the rate of disappearance will be more uniform within a given patient population.

There is still pharmacodynamic variability with remifentanil, and the endpoint for titration is no different than that with other opioids. Unlike older opioids, however, accurate dosing of remifentanil is not quite as critical because rapid recovery is effectively doseindependent (Rosow et al. 1999). In theory, remifentanil could be used in any clinical situation calling for a potent opioid analgesic, e.g. remifentanil can be administered in doses that would be impractical or hazardous with other fentanyl derivatives because of its rapid offset. In addition, remifentanil can be used at higher analgesic doses without concern for residual opioid effects, mainly respiratory depression. The principal problem with utilizing its unique characteristics in an emergency situation is that unlike other opioids, remifentanil is limited to intravenous administration only.

Non-traditional routes of administration of remifentanil and other opioids

Nasal administration of opioids is broadly used for acute severe pain when a rapid onset is needed, e.g. treatment of breakthrough pain in oncologic patients. Bioavailability of nasal administration of drugs is influenced by many factors, e.g. size of the molecule, lipid solubility, $\mathrm{pH}$ of the solvent and $\mathrm{pKa}$ of the drug, its concentration, volume, distribution of solution, and route/method of administration, e.g. sprays have higher bioavailability than nasal drops. There is published data to suggest that there is direct communication between the nasal cavity and brain via perineural space. Drugs are absorbed through the olfactory area directly into the subarachnoid space (Suter-Zimmermann 2008, Hess et al. 2016). The advantage of nasal administration of opioids in humans is non-invasiveness, high compliance even in children, and good bioavailability. This route is already available for fentanyl clinical use (e.g. INSTANYL Nycomed), and the route has been studied for sufentanil (Henderson et al. 1988, Karl et al. 1992, Nielsen et al. 2014, Hronova et al. 2016) and alfentanil (Brenchley and Ramlakhan 2006). There has only been one trial using the nasal route with remifentanil in humans, i.e. a dose of $4 \mu \mathrm{g} / \mathrm{kg}$ was given nasally to facilitate intubation in children (Verghese et al. 2008). Nasal administration of remifentanil was also tested in animals in a pilot study by the authors of this project (Hess et al. 2012a). The results were promising, i.e. the onset was rapid, duration was longer than after IV injection, and side effects were less prominent. Moreover, the specific opioid antidote, naloxone, is also effective when given intranasally (Kelly et al. 2005) and has been approved in the United States by the FDA for use in heroin overdoses. 
Intramuscular administration is the standard route of administration of many injectable forms of drugs. The onset of effect can be accelerated by the administration into the deltoid muscle instead of the gluteus muscle (Reynolds et al. 1996, Reynolds et al. 1997, Hess et al. 2012b) as well as with the addition of hyaluronidase (Hess et al. 2010). There are no published results concerning the intramuscular administration of remifentanil, although its efficacy in animals has been demonstrated (unpublished personal experiences).

Conjunctival administration is rarely used in human medicine despite case reports of life-threatening intoxication by the accidental administration of potent opioids to the eye (Riviere and Papich 2003). It is well known that some ophthalmic drugs are easily absorbed into the systemic circulation. There is a report of the efficacy of ocular administration of naloxone in humans associated with heroin abuse (Duncalf et al. 1975, Ghodse et al. 1995). In animal experiments, sufentanil (Farnsworth et al. 1998, Malek et al. 2011), buprenorphine (Malek et al. 2012), and fentanyl (Zöllner et al. 2008) have been tested, and remifentanil was tested in our pilot study (Malek et al. 2012).

The aim of this study was to explore the feasibility and safety of administering remifentanil using nasal, conjunctival, and intramuscular routes of administration. Our hypothesis was that remifentanil administered by these routes 1) would be absorbed rapidly, 2) would be pharmacologically active, 3) would have a rapid onset and rapid recovery, and 4) in the case of conjunctival administration, would be non-injurious to rabbit conjunctiva. The second aim of this experimental study was to assess the dose-effect relation with respect to plasma concentrations relative to the route of administration of remifentanil (i.e. nasal, conjunctival, and intramuscular). To our best knowledge, no such series of experiments using these routes of administration have been done except for previous pilot studies (Hess et al. 2012c, Malek et al. 2012).

\section{Methods}

\section{Experimental animals}

We used New Zealand White rabbits weighing 2.5-4.5 kg of both sexes. Ten animals were used for each test. Rabbits were bred in individual cages at a temperature of $20-22{ }^{\circ} \mathrm{C}$ and air humidity of $40-65 \%$. They were fed a standard diet with unlimited access to water. The experiments were approved by the Ethics
Committee for Animal Experiments of the Czech Ministry of Public Health and IKEM.

\section{Obtaining data}

Cardiorespiratory parameters (hemoglobin oxygen saturation $\left(\mathrm{SpO}_{2}\right)$, pulse, and blood pressure) were measured after $15 \mathrm{~min}$ of acclimatization to the laboratory environment. The probe for pulse oximetry was applied to an area of shaved skin on the back of the neck of the animals, and non-invasive blood pressure (NIBP) was measured on the thoracic extremity using a Memoprint monitor (Medvet, Germany) at $5 \mathrm{~min}$ intervals. The first measurements were performed before administration of remifentanil and continued at $1 \mathrm{~min}$ intervals, except for NIBP for $20 \mathrm{~min}$. The first signs of sedation included decreased vibrissae movements, decreased muscle tone, and a change in body position. The animals' reaction to tapping on its forehead was assessed, and immobilization time was measured as the appearance of the loss of the righting reflex. The onset of the loss of righting reflex was tested by placing the animal in a prone position at $1 \mathrm{~min}$ intervals and observing the reflex response.

\section{Experiments}

We tested two doses of intramuscular remifentanil, $1.0 \mu \mathrm{g} / \mathrm{kg}$ and $3.0 \mu \mathrm{g} / \mathrm{kg}$, injections of remifentanil were into the musculus semitendinosus. Nasal and conjunctival doses of remifentanil were $10.0 \mu \mathrm{g} / \mathrm{kg}$ and $25.0 \mu \mathrm{g} / \mathrm{kg}$, and $5.0 \mu \mathrm{g} / \mathrm{kg}$ and $10.0 \mu \mathrm{g} / \mathrm{kg}$, respectively. All doses were chosen with respect to our pilot experiments and literature data. Nasal and conjunctival administrations were done using cannula with a spherical tip to avoid injury. Signs of eye irritation were measured using the modified state regulation CSN EN ISO 10993-10 and macro-photos were taken.

Dose-effect relationships were tested and compared for each group of animals (i.e. the onset of sedation and immobilization, loss of the righting reflex, and cardiorespiratory parameters, which were taken at baseline and 1, 10, and $20 \mathrm{~min}$ after administration). The dose ranges used in this experiment were previously tested in pilot experiments.

\section{Plasma concentration analyses}

In selected animals, plasma levels of remifentanil were measured at two intervals: immediately after the loss of the righting reflex and $10 \mathrm{~min}$ after. Blood samples were drawn from the vena auricularis into 
plastic tubes containing citrate buffer with a $\mathrm{pH}=4.2$, which prevented spontaneous hydrolysis of remifentanil at a basic $\mathrm{pH}$ or by non-specific plasma esterases. After centrifugation for $5 \mathrm{~min}$ at $3,750 \mathrm{~g}$, blood plasma was obtained and immediately frozen using liquid nitrogen and stored in a freezer at $-20^{\circ} \mathrm{C}$. Liquid-liquid extraction (LLE) or solid-phase extraction (SPE) was used for sample preparation (Jacek et al. 2013, Kabbaj and Varin 2003). Analysis of samples was performed on a gas chromatograph with a nitrogen-phosphorous detector (NPD), which is more selective and sensitive for nitrogen-containing compounds than the common flame ionization detector (FID).

\section{Statistical analysis}

The Shapiro-Wilk W statistics was used to test normality. ANOVA with repeated measures was used for analysis within groups and between groups for data with a normal distribution. For data, which after transformation (logarithm, square root) did not have a normal distribution, non-parametric methods, i.e. the Friedman analysis and Kruskal-Wallis analysis, were used. Bonferroni corrections were used for multiple comparisons. All tests were two-sided, and a $\mathrm{P}<0.05$ was assumed to be statistically significant.

\section{Results}

\section{Loss of righting reflex}

The administration of remifentanil at doses of $3.0 \mu \mathrm{g} / \mathrm{kg} \mathrm{IM}, 10.0 \mu \mathrm{g} / \mathrm{kg}$ and $25.0 \mu \mathrm{g} / \mathrm{kg}$ nasally and $5.0 \mu \mathrm{g} / \mathrm{kg}$ and $10.0 \mu \mathrm{g} / \mathrm{kg}$ conjunctivally resulted in a loss of the righting reflex (mean \pm SD) by $143.0 \pm 84.7 \mathrm{~s}$, $165.0 \pm 92.9 \mathrm{~s}, \quad 111.5 \pm 38.6 \mathrm{~s}, \quad 123.6 \pm 65.8 \mathrm{~s}, \quad$ and $187.0 \pm 110.2 \mathrm{~s}$, respectively (Fig. 1). At the lowest IM dose $(1.0 \mu \mathrm{g} / \mathrm{kg})$, there was virtually no loss of the reflex. The effect subsided in half of the experimental animals within $20 \mathrm{~min}$ of the application. This data was not evaluated statistically.

\section{Pulse rate}

The two-way repeated ANOVA showed no significant effect between the six treatments on the pulse rate (Fig. 2).

\section{Pulse rate}

The two-way repeated ANOVA showed no significant effect between the six treatments on the pulse rate (Fig. 2).

\section{Arterial blood pressure}

The two-way repeated ANOVA showed no significant effect between the six treatments on the systolic, diastolic, or mean arterial blood pressure (Fig. 3).

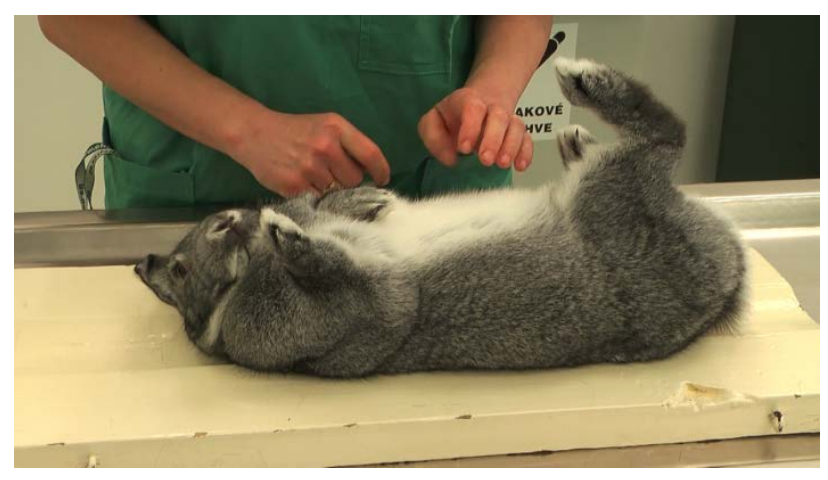

Fig. 1. Rabbit with loss of the righting reflex.

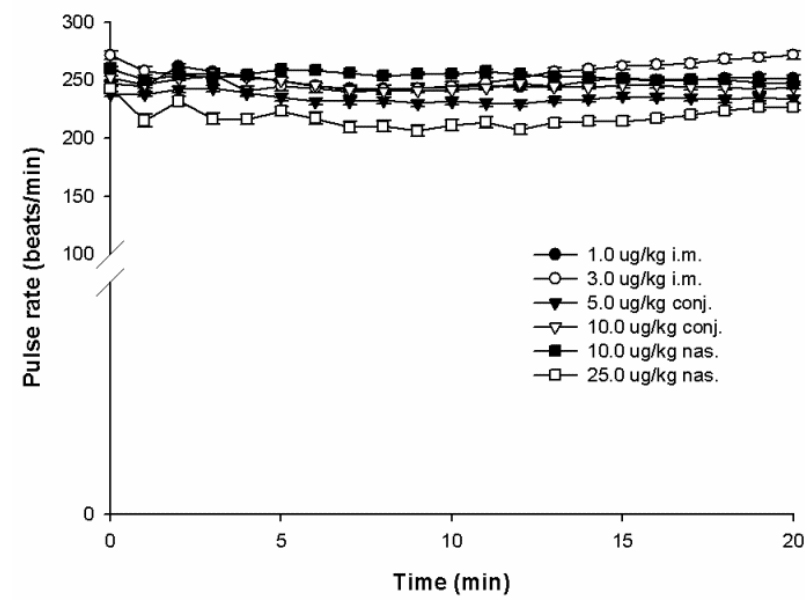

Fig. 2. Pulse rate.

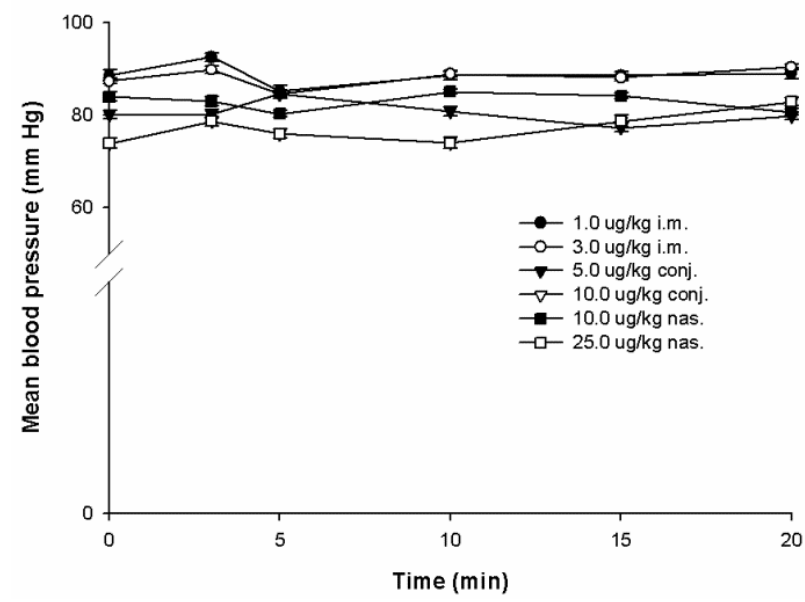

Fig. 3. Mean arterial blood pressure. 


\section{Arterial oxygen saturation of hemoglobin}

The two-way repeated ANOVA showed no significant effect between the six treatments on the $\mathrm{SpO}_{2}$ (Fig. 4).

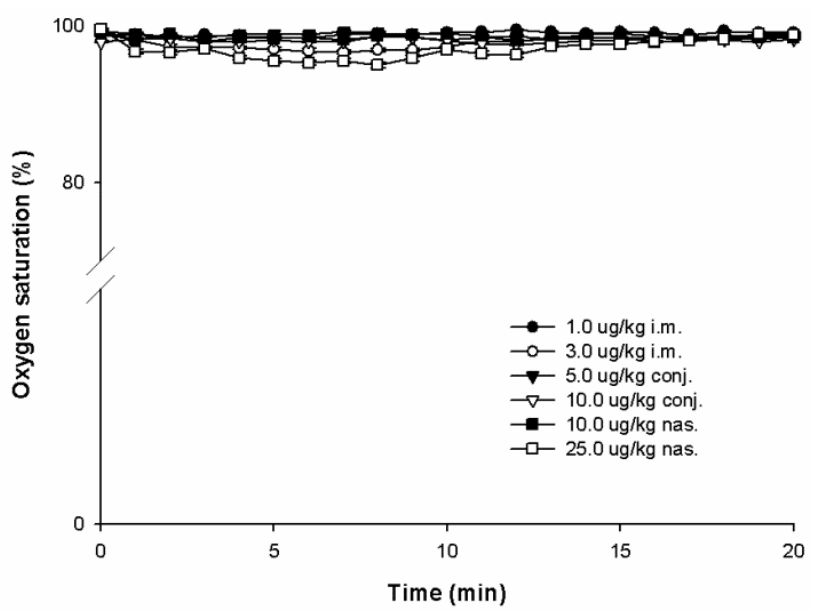

Fig. 4. Arterial oxygen saturation of hemoglobin.

\section{Plasma concentrations}

As mentioned previously, plasma concentrations were measured as secondary endpoints only. Because of the limited amount of data, a meaningful statistical evaluation could not be done. Nevertheless, the measured concentrations were very similar across all the experimental groups suggesting very good absorption for both the conjunctival and nasal routes of administration.

\section{Discussion}

The results showed that the onset of action of remifentanil, as measured by the loss of the righting reflex, was rapid and its duration was short, i.e. in $50 \%$ of applications the effect stared to reverse within $20 \mathrm{~min}$. Thus, the loss of the righting reflex was doseindependent. Importantly, and from the clinical point of view, cardiorespiratory parameters were insignificantly affected. Although a significant decrease in heart rate is characteristic of opioids, the heart rate after remifentanil decreased statistically insignificantly in all treatment groups (except the highest conjunctival dose). Similarly, other primary endpoints (arterial oxygen saturation and mean blood pressure), including respiration, were also clinically insignificantly affected. Notably, there were no signs of conjunctival irritation following administration via this route (Fig. 5).

The intranasal route of opioid administration is an effective and rapid method of achieving analgesia in
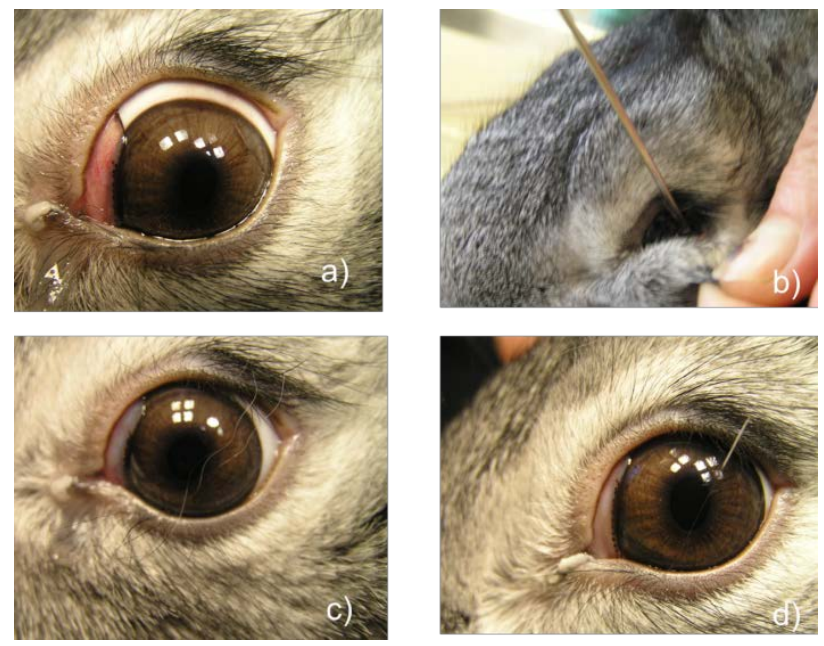

Fig. 5. No signs of conjunctival irritation (a) before instillation, (b) instillation, (c) $10 \mathrm{~min}$ after instillation, and (d) $20 \mathrm{~min}$ after instillation.

adults and children when intravenous access is not available (Heshmati et al. 2006, Manjushree et al. 2002, Corrigan et al. 2015). Intranasally administered medications are delivered directly to the central nervous system, thus avoiding first-pass metabolism. The onset of action after nasal administration is known to be rapid. Additionally, the bioavailability of opioids through this route, including fentanyl, and sufentanil, is very high, i.e. $70-80 \%$ (Prommer and Thompson 2011). Both fentanyl and sufentanil are used in this way, but nasal administration of remifentanil has only been described in two studies concerning potentiation of anesthesia in children (Verghese et al. 2008) and one very recent experimental study on rodents concerning inhalational administration of remifentanil (Bevans et al. 2016). To our best knowledge, this is the first study measuring the dose-effect relationship using the nasal route of administration of remifentanil under controlled conditions in experimental animals.

We demonstrated that non-traditional routes of administration of remifentanil were equally effective as other methods of administration, i.e. intramuscular administration (bearing in mind that remifentanil use in humans is only approved for intravenous administration, hence, even the intramuscular route could be considered non-traditional for this drug). Importantly, both intranasal and conjunctival routes were associated with good safety with comparable (e.g. negligible) effects on arterial blood pressure, arterial oxygen saturation of hemoglobin, and pulse rate.

Unlike existing opioids, remifentanil exhibits a predictable, rapid metabolism by non-specific esterases 
in the blood and tissues, principally to a carboxylic acid derivative, remifentanil acid. Remifentanil after IV administration has a rapid onset of action and a short latency to its peak effect. Remifentanil (remifentanil hydrochloride) is an opioid with a rapid onset of action (about $1 \mathrm{~min}$ ) and quickly achieves a steady state. It has a context-sensitive half-life of $2 \pm 3 \mathrm{~min}$, which is independent of the infusion duration (Hayashida et al. 2006). Remifentanil is not a substrate for plasma cholinesterase, and therefore its metabolism is not subject to genetic variance. Compared to the IV route, the effect after nasal, IM, and conjunctival administration is different, i.e. the onset is delayed and the duration prolonged.

Based our experimental data, we believe that remifentanil meets all the criteria for nasal administration. Compared to intramuscular administration, the therapeutic index after nasal administration was substantially higher. Equally important is that the selective antidote for opioids, naloxone, can be administered nasally as well (Lynn and Galinkin 2018). Intramuscular administration of remifentanil showed signs of respiratory depression (not reported here) from as low as $10 \mu \mathrm{g} / \mathrm{kg}$. Moreover, its effect was short in duration.

In conclusion, remifentanil proved to be an effectively acting opioid when administered via non-traditional routes in rabbits. This makes the molecule of remifentanil very promising in emergent clinical situations. Nonetheless, other studies are highly warranted.

\section{Conflict of Interest}

There is no conflict of interest.

\section{Acknowledgements}

This work was supported by PROGRESS Q 35.

\section{References}

AUSEMS ME, HUG CC JR, STANSKI DR, BURM AGL: Plasma concentrations of alfentanil required to supplement nitrous oxide anesthesia for general surgery. Anesthesiology 65: 362-367, 1986.

BEVANS T, DEERING-RICE C, STOCKMANN C, LIGHT A, REILLY C, SAKATA DJ: Inhaled Remifentanil in Rodents. Anesth Analg 122: 1831-1838, 2016.

BRENCHLEY J, RAMLAKHAN S: Intranasal alfentanil for acute pain in children. Emerg Med J 23: 488, 2006.

CORRIGAN M, WILSON SS, HAMPTON J: Safety and efficacy of intranasally administered medications in the emergency department and prehospital settings. Am J Health Syst Pharm 72: 1544-1554, 2015.

DUNCALF D, JEYARAM C, TARTER R, FOLDES FF: Ocular absorption of naloxone in narcotic addicts. Int J Addict 10: 23-27, 1975.

FARNSWORTH ST, GAUTHIER ME, MCJAMES SW, ZHANG J, MAMALIS N, KOPP CH: Ocular transmucosal absorption and toxicity of sufentanil in dogs. Anesth Analg 86: 138-140, 1998.

GALINSKI M, RUSCEV M, GONZALEZ G, KAVAS J, AMEUR L, BIENS D, LAPOSTOLLE F, ADNET F: Prevalence and management of acute pain in prehospital emergency medicine. Prehosp Emerg Care 14: 334-339, 2010.

GHODSE H, TAYLOR DR, GREAVES JL, BRITTEN AJ, LYNCH D: The opiate addiction test: a clinical evaluation of a quick test for physical dependence on opiate drugs. Br J Clin Pharmacol 39: 257-259, 1995.

GLASS PSA, GAN TJ, HOWELL S: A review of the pharmacokinetics and pharmacodynamics of remifentanil. Anesth Analg 89 (4 Suppl): S7-S14, 1998.

HAYASHIDA M, FUKUNAGA A, FUKUDA K, SAKURAI S, MAMIYA H, ICHINOHE T, KANEKO Y, HANAOKA K: The characteristics of intravenous adenosine-induced antinociception in a rabbit model of acute nociceptive pain: a comparative study with remifentanil. Anesth Analg 103: 1004-1010, 2006.

HENDERSON JM, BRODSKY DA, FISCHER DM, BRET CM, HERTZKA RE: Pre-induction of anesthesia in pediatric patients with nasally administered sufentanil. Anesthesiology 68: 671-675, 1988.

HESHMATI F, NOROOZINIA H, ABBASIVASH R, MAHOORI A GHARAEE H: Intranasal sufentanil for postoperative pain control in lower abdominal pediatric surgery. IJPT 5: 131-133, 2006.

HESS L, VOTAVA M, SCHREIBEROVA J, MALEK J, HORACEK M: Experience with a naphthylmedetomidineketamine-hyaluronidase combination in inducing immobilization in anthropoid apes. J Med Primatol 39: 151-159, 2010. 
HESS L, MALEK J, KURZOVA A: Nasal administration of remifentanil in rabbits. Eur J Anaesthesiol 29 (Suppl): 140, 2012a.

HESS L, MALEK J, KURZOVA A, VOTAVA M: The effect of site (deltoid or gluteus muscle) of intramuscular administration of anaesthetic drugs on the course of immobilisation in macaque monkeys (Macaca mulatta). Acta Vet Brno 81: 207-210, 2012b.

HESS L, MALEK J, KURZOVA A, JACEK M, MATEJCKOVA J, VOTAVA M: Conjunctival administration of buprenorphine in rabbits. Pain Pract 12: 19-20, 2012c.

HESS L, VOTAVA M, MALEK J, KURZOVA A, SLIVA J: Sedative effects of intranasal oxytocin in rabbits and rhesus monkeys. Physiol Res 65 (Suppl 4): S473-S480, 2016.

HRONOVA K, POKORNA P, POSCH L, SLANAR O: Sufentanil and midazolam dosing and pharmacogenetic factors in pediatric analgosedation and withdrawal syndrome. Physiol Res 65 (Suppl 4): S463-S472, 2016.

HUGHES MA, GLASS PSA, JACOBS JR: Context-sensitive half-time in multicompartment pharmacokinetic models for intravenous anesthetic drugs. Anesthesiology 76: 334-341, 1992.

JACEK M, MATEJCKOVA J, MALEK J, HESS L, SAMCOVA E: Determination of midazolam in rabbit plasma by GC and LC following nasal and ocular administration. J Sep Sci 36: 3366-3371, 2013.

KABBAJ M, VARIN F: Simultaneous solid-phase extraction combined with liquid chromatography with ultraviolet absorbance detection for the determination of remifentanil and its metabolite in dog plasma. $J$ Chromatogr B 783: 103-111, 2003.

KARL HW, KEIFER AT, ROSENBERGER JL, LARACH MG, RUFFLE JM: Comparison of the safety and efficacy of intranasal midazolam or sufentanil for preinduction of anesthesia in pediatric patients. Anesthesiology 76: 209-215, 1992.

KELLY AM, KERR D, DIETZE P: Randomised trial of intranasal versus intramuscular naloxone in prehospital treatment for suspected opioid overdose. MJA 182: 24-27, 2005.

LYNN RR, GALINKIN JL: Naloxone dosage for opioid reversal: current evidence and clinical implications. Ther Adv Drug Saf 9: 63-88, 2018.

MALEK J, HESS L, KURZOVA A: Conjunctival administration of remifentanil in rabbits. Eur J Anaesthesiol 29 (Suppl): 139-140, 2012.

MANJUSHREE R, LAHIRI A, GHOSH BR, LAHA A, HANDA K: Intranasal fentanyl provides adequate postoperative analgesia in pediatric patients. Can J Anaesth 49: 190-193, 2002.

NIELSEN BN, FRIIS SM, RØMSING J, SCHMIEGELOW K, ANDERSON BJ, FERREIROS N, LABOCHA S, HENNEBERG SW: Intranasal sufentanil/ketamine analgesia in children. Paediatr Anaesth 24: 170-180, 2014.

PROMMER E, THOMPSON L: Intranasal fentanyl for pain control: current status with a focus on patient considerations. Patient Prefer Adherence 5: 157-164, 2011.

REYNOLDS LM, LAU M, BROWN R, LUKS A, FISHER DM: Intramuscular rocuronium in infants and children. Dose-ranging and tracheal intubating conditions. Anesthesiology 85: 231-239, 1996.

REYNOLDS LM, LAU M, BROWN R, LUKS A, SHARMA M, FISHER DM: Bioavailability of intramuscular rocuronium in infants and children. Anesthesiology 87: 1096-1105, 1997.

RIVIERE JE, PAPICH MG: Veterinary Pharmacology and Therapeutics. $9^{\text {th }}$ edition, Wiley-Blackwell, Iowa, 2009.

ROSOW CE: An overview of remifentanil. Anesth Analg 89 (4 Suppl): S1-S3, 1999.

SUTER-ZIMMERMANN K: Transmucosal Nasal Drug Delivery, Systemic Bioavailability of Nasaly Applied Midazolam. Dissertation, Basel, 2008.

VERGHESE ST, HANNALLAH RS, BRENNAN M, YARVITZ JL, HUMMER KA, PATEL KM, HE J, MCCARTER $\mathrm{R}$ : The effect of intranasal administration of remifentanil on intubating conditions and airway response after sevoflurane induction of anesthesia in children. Anesth Analg 107: 1176-1181, 2008.

WESTMORELAND CL, HOKE JF, SEBEL PS, HUG CC JR, MUIR KT: Pharmacokinetics of remifentanil (GI87084B) and its major metabolite (GR90291) in patients undergoing elective surgery. Anesthesiology 79: 893-903, 1993.

ZÖLLNER C, MOUSA S, KLINGER A, FÖRSTER M, SCHÄFER M: Topical fentanyl in a randomized, double-blind study in patients with corneal damage. Clin J Pain 24: 690-696, 2008. 